\title{
Toughening of Alumina Ceramics with Silver Nanoparticles
}

\section{Azucena Pérez de la Fuente, Enrique Rocha Rangel, José Amparo Rodríguez García and Constantin Alberto Hernández-Bocanegra}

\author{
Universidad Politécnica de Victoria, Parque Científico y \\ Tecnológico de Tamaulipas, Ciudad Victoria, Tamaulipas, México
}

Correspondence should be addressed to: Enrique Rocha Rangel; erochar@upv.edu.mx

Received date: 14 july 2014; Accepted date: 24 september 2014; Published date: 1 September 2016

Accademic Editor: S. Ram

Copyright (C) 2016. Azucena Pérez de la Fuente, Enrique Rocha Rangel, José Amparo Rodríguez García and Constantin Alberto Hernández-Bocanegra. Distributed under Creative Commons CC-BY 4.0

\begin{abstract}
In this study ceramic materials with an $\mathrm{Al}_{2} \mathrm{O}_{3}$-matrix toughened with different amounts of Ag nanoparticles (0.0, 0.5, 1.0, 2.0 and 3.0 wt. \%) were fabricated. High energy milling was used to mix the materials in a planetary mill type, in which powder particles with sizes of $\sim 300 \mathrm{~nm}$ were obtained. With the milled powders, they were fabricating cylindrical samples by uniaxial pressing. Then, compacted samples were sintered in an electrical furnace at different temperatures $\left(1400^{\circ} \mathrm{C}, 1500^{\circ} \mathrm{C}\right.$ and $\left.1600^{\circ} \mathrm{C}\right)$ and during different times $(1,2$ and $3 \mathrm{~h}$ ). Microstructure observations were made with optical microscopy and scanning electron microscopy, observing in both cases dense composites with very fine microstructures. Concerning the measurement results of fracture toughness, which were estimated by the indentation fracture method, it was shown that the composites made by mean procedure present higher values than the average of the monolithic alumina, up to $400 \%$. It was determined that the reinforcement mechanism of these materials is due to the deflection of cracks owing to metallic bridges formed by the silver used as alumina strengthener.
\end{abstract}

Keywords: Toughening, $\mathrm{Al}_{2} \mathrm{O}_{3}$-ceramics, Silver, Nanoparticles

\section{Introduction}

Ceramic materials generally are very fragile; in the case of materials made of alumina $\left(\mathrm{Al}_{2} \mathrm{O}_{3}\right)$ are no exceptions. In the book of Auerkari (1996) it is mentioned that alumina is a widely useful industrial ceramic material. Its applications include high-speed cutting tools, dental implants, prostheses, electrical and thermal insulators and wear-resistant between others. Its usefulness is attributed to its high hardness and high compressive strength. However, despite their enviable features and potential in agreement with Liu et al (2007), its use as a structural material has been significantly hampered by its low fracture toughness. Ceramic

Cite this Article as: Azucena Pérez de la Fuente, Enrique Rocha Rangel, José Amparo Rodríguez García and Constantin Alberto Hernández-Bocanegra (2016), " Toughening Of Alumina Ceramics with Silver Nanoparticles", Journal of Research in Nanotechnology , Vol. 2016 (2016), Article ID 957063, 
materials can be toughened by incorporation into the matrix of fine particles of metals. This development has been successfully employed previously in different systems Oh et al (1998), Naga et al (2007), Li et al (2002) and Miranda et al (2006). Some researchers as Daguano et al (2007) showed that it is possible to increase the flexural strength, elastic modulus and tensile strength of the porous alumina by increasing the residence time at temperatures below $1050{ }^{\circ} \mathrm{C}$. If the residence time is increased, this leads to an increase in the surface diffusion, and therefore an increase in the mechanical strength. Reinforcement models indicate that it is very important the nonmetallic inclusion size and the homogeneous distribution thereof in the ceramic matrix, in order to ensure obtaining a composite material with good toughness properties Ighodaro and Okoli (2008), Ko et al (2002) and Agrawal and Sun (2004). Therefore, considerable efforts have been made to establish optimal conditions for processing and thus to obtain compounds with the desired microstructure and properties as example Konopka and Szafran (2006) fabricated an $\mathrm{Al}_{2} \mathrm{O}_{3} / \mathrm{Al}$ composite by the infiltration method, Sternizke et al (1996) have evaluated the wear properties of Alumina/Aluminum Composites with Interpenetrating Networks, Marci and Katarzyna (2007) manufactured an $\mathrm{Al}_{2} \mathrm{O}_{3} / \mathrm{Cr}$ composite, Lieberthal and Kaplan (2001) fabricated an $\mathrm{Al}_{2} \mathrm{O}_{3}$ ceramic reinforced with submicron $\mathrm{Ni}$ and $\mathrm{NiAl}_{2} \mathrm{O}_{4}$, Sekino et al (1997) fabricated a NickelDispersed-Alumina Composite and Travirskya et al (2003) manufactured Alumina-Ti aluminide interpenetrating composites. The main problem with the related processes is that all of them are very complex and present low production. Conventional powder method is a low-cost method in which a good sintered product can be obtained. The goal of this study is to synthesize alumina-based composites reinforced with silver nanoparticles through the combination of high energy milling and pressureless sintering, and to determine the effect of silver on the fracture toughness of the ceramic matrix.

\section{Experimental}

$\mathrm{Al}_{2} \mathrm{O}_{3}$ (Mayer, 99.9\% purity, $1-2 \mu \mathrm{m}$ ), and Ag (Sigma-Aldrich, 99.9\% purity, $5 \mu \mathrm{m}$ ) powders were used in this study. Five systems were studied, being $\mathrm{Al}_{2} \mathrm{O}_{3}$ the principal component, whereas the content of Ag has varied according to the following contents: $(0.0,0.5,1.0,2.0$ and 3.0 wt. \%). With the help of a planetary mill (Retsch, PM100, Germany) powders were mixed and ground using YZT grinding spherical elements of $0.3 \mathrm{~cm}$ diameter, using a cylindrical stainless steel vessel. The milling was carried out for 3 hours at 250 rpm in dry. The ratio between powder weight and ball weight was 1:14. In order to determine the size of the powders, after grinding, the powders were analyzed in granulometric equipment (Malvern Instruments, Masterziser 2000, UK). Cylindrical samples of each composition were compacted using $350 \mathrm{MPa}$ pressure with the aid of a uniaxial press (Montequipo, LAB-30-G, Mexico). The size of the samples was $2 \mathrm{~cm}$ of diameter and $0.3 \mathrm{~cm}$ thickness. Sintering of the samples was carried out in an electric resistance furnace, (Carbolite RHF17/3E, UK), at different temperatures $\left(1400^{\circ} \mathrm{C}, 1500^{\circ} \mathrm{C}\right.$ and $1600^{\circ} \mathrm{C}$ ) during different times $(1,2$ and $3 \mathrm{~h}$ ). To inhibit silver oxidation, a flux of argon of $10 \mathrm{~cm}^{3} / \mathrm{min}$ was injected inside the furnace. Determinations of sample's densities were performed by the Archimedes principle. The fracture toughness was estimated by the indentation fracture method, using a Vickers microhardness tester (Wilson Instruments, S400) and applying Evans and Charles equation (1976). To observe the microstructure, an optical microscope (Nikon Eclipse, MA200, Japan), and a scanning electron microscope (SEM-JEOL, Japan 6300) were used. The SEM is equipped with an energy dispersive detector X-rays (EDX) (Hitachi, UHR FESEM SU9000, Japan).

\section{Analysis and Results Discussion}

\section{Granulometry}

The particle size distribution for different samples is shown in Fig. 1. In this figure it can be observed that in all samples, 
powders with particles sizes up to $300 \mathrm{~nm}$ were obtained, also over $50 \%$ of the size of the powders is less than 1 micron, and these two aspects prove that nanometric sizes are mainly obtained in the powder during the milling step. Also in the figure it is observed the presence of big size particles that could be due to the agglomeration of very small particles. Because there are very small particles in the samples, contact between them has to be very large, situation has to favor diffusion process during their sintering.

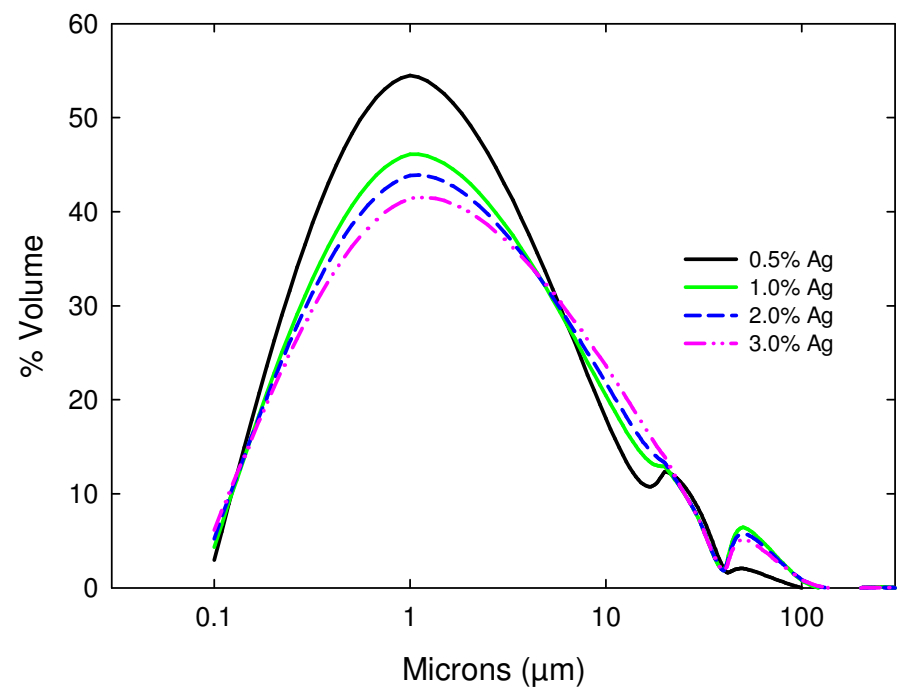

Figure1: Granulometric distribution of particles in the different studied systems

Fig. 2 shows scanning electron micrographs of milled powders with different amounts of silver. In this figure, it can be observed in all cases the presence of very fine powders with sizes less than 1 $\mu \mathrm{m}$, also the presence of agglomerates of various sizes formed with very fine powders is perceived.

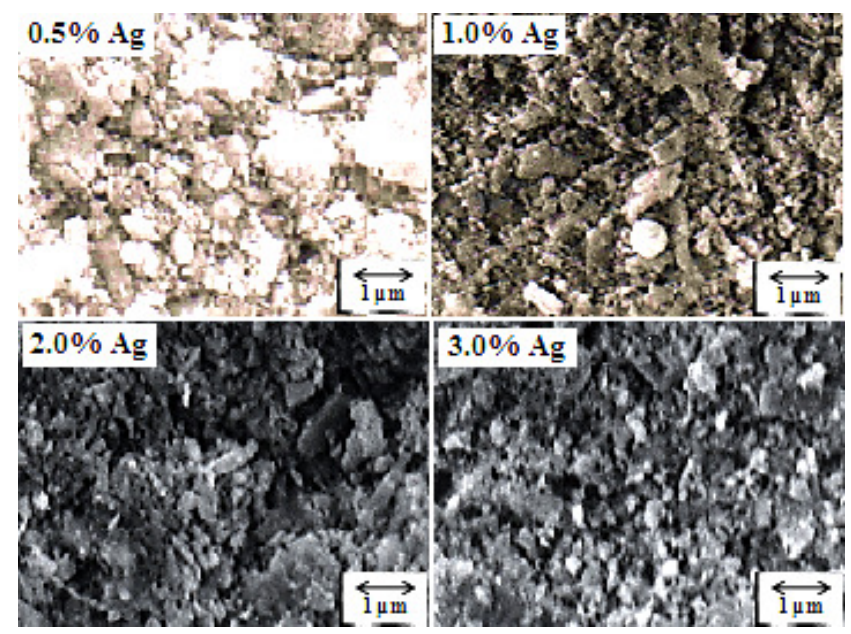

Figure2: Scanning electron micrographs of milled powders with different amounts of silver 


\section{Density}

Fig. 3 Presents results of density measurements of the sintered samples. In samples sintered at $1500{ }^{\circ} \mathrm{C}$ during $2 \mathrm{~h}$ (Fig. 3a), samples with contents of $1.0 \%$ and $2.0 \%$ present the highest density values; however, all samples have reached values bigger than $98 \%$ of their relative density. These results are due to the presence of very fine particles in samples. Fine particles favor powders compaction and therefore, a homogeneous grain growth during the sintering. In samples sintered for $2 \mathrm{~h}$ with variations of the temperature (Fig. 3b), the positive effect of temperature is observed, attaining the highest value of density ( $99.7 \%$ ) at 1600 ${ }^{\circ} \mathrm{C}$. Definitely, diffusion processes are more effective at this temperature when it has the presence of silver in the system, which may be due to that silver at this temperature is in liquid phase which promotes sintering mechanisms. Regarding the samples sintered at $1500{ }^{\circ} \mathrm{C}$ for different times 1, 2 and $3 \mathrm{~h}$ (Fig. 3c), the positive effect of time on density is similarly observed up to $1500{ }^{\circ} \mathrm{C}$. Densities of samples are almost $99.5 \%$ when they are sintered at $1500{ }^{\circ} \mathrm{C}$ during $3 \mathrm{~h}$. From all these results it can be said that, the sintering combination of low temperature $\left(1400{ }^{\circ} \mathrm{C}\right)$ with low time $(1 \mathrm{~h})$, are not favorable conditions for consolidating samples; in this case diffusion is not large enough to achieve the densification of the samples.

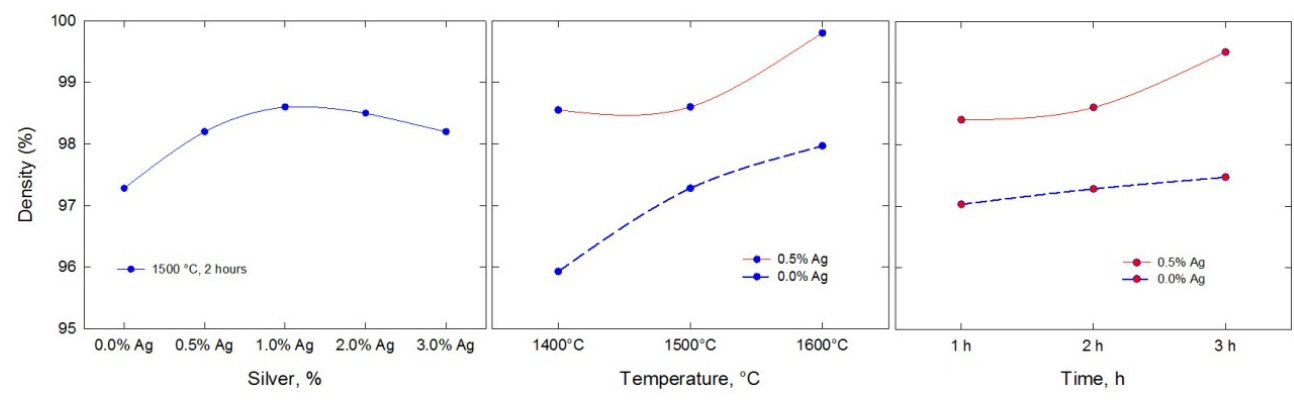

Figure: 3 Relative densities of the sintered samples with inclusions of $\mathrm{Ag}$

\section{Microstructure}

Fig. 4 shows optical micrographs corresponding to samples with different contents of $\mathrm{Ag}$ sintered at $1500{ }^{\circ} \mathrm{C}$ during 2 h. It may be observed that there is a slight grain growth with increments of silver content. However, the final grain size in all samples is very fine, this is due to the good thermal conductivity of $\mathrm{Ag}$ that adequately dissipates a good portion of the thermal energy generated during sintering; thereby contributing to obtain the good values of densification showed in the previous section and fine microstructures observed here. 


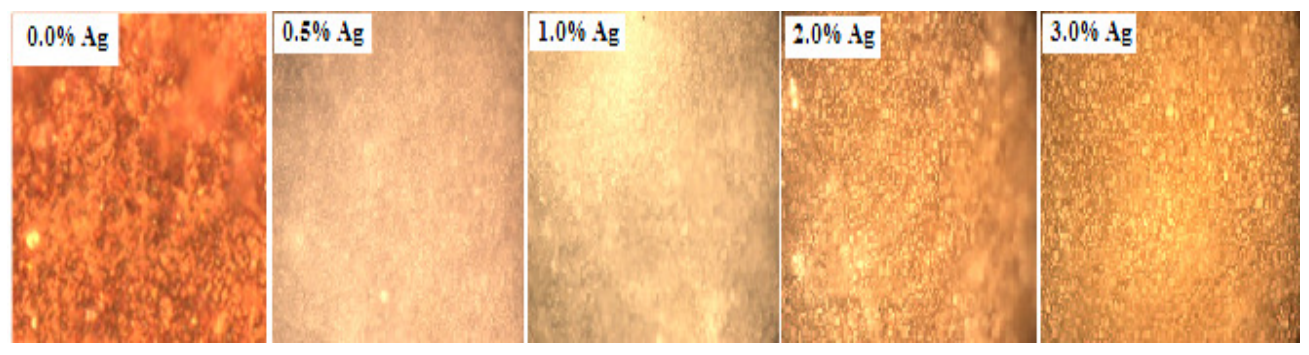

Figure 4: Micrographs of the sintered samples at $1500^{\circ} \mathrm{C}$ during 2 hours

Fig. 5 shows optical microscope pictures of the microstructure of samples with $0.5 \mathrm{wt}$. $\% \mathrm{Ag}$ sintered at different times and temperatures. In this case, it is possible to see (observe figure from left to right) that the grain growth is not significant with temperature and time increments. These results agree with those shown in the previous sections.

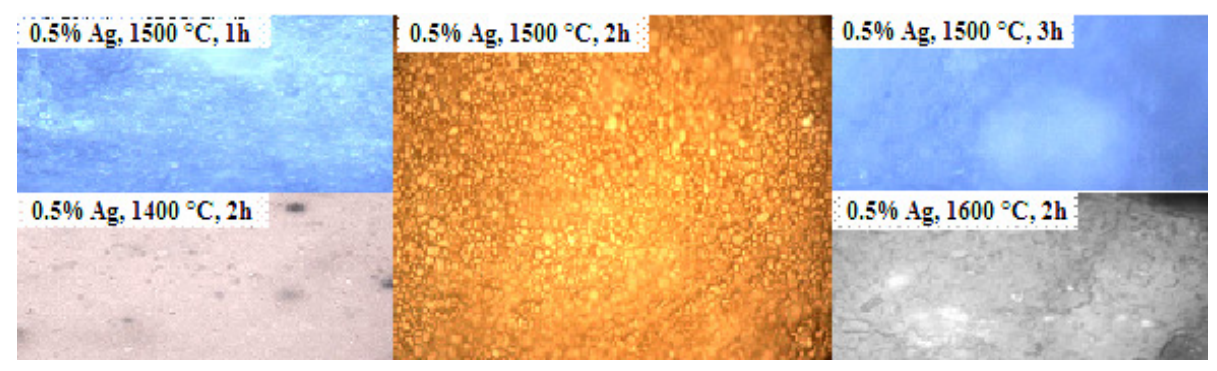

Figure 5: Photomicrographs corresponding to the 0.5 wt. \% Ag sintered samples, varying time and temperature

Fig. 6 Presents images of the microstructures observed with the help of a scanning electron microscope of samples sintered at $1500{ }^{\circ} \mathrm{C}$ for 2 hours. The sample without inclusions of $\mathrm{Ag}$ has an uncontrolled growth of grain sizes, observing grains greater than $20 \mu \mathrm{m}$. Regarding samples with $\mathrm{Ag}$ inclusions, a more uniform size and better grain distributed is observed. As the Ag amount increases in the sample, grain size grows too, which matches very well with the results of relative density of the sintered samples and optical microscope observations. Also in figure 6 it can be observed the presence of very small clear particles located in intergranular positions of the matrix. X-rays energy dispersive (EDX) punctual analyses were performed in the dark and clear phases presented in the microstructures of figure 6. Spectra resulting from these analyses are presented in Fig. 7. According to these spectra, the dark phase must correspond to the ceramic matrix, while the clear phase corresponds to silver. 


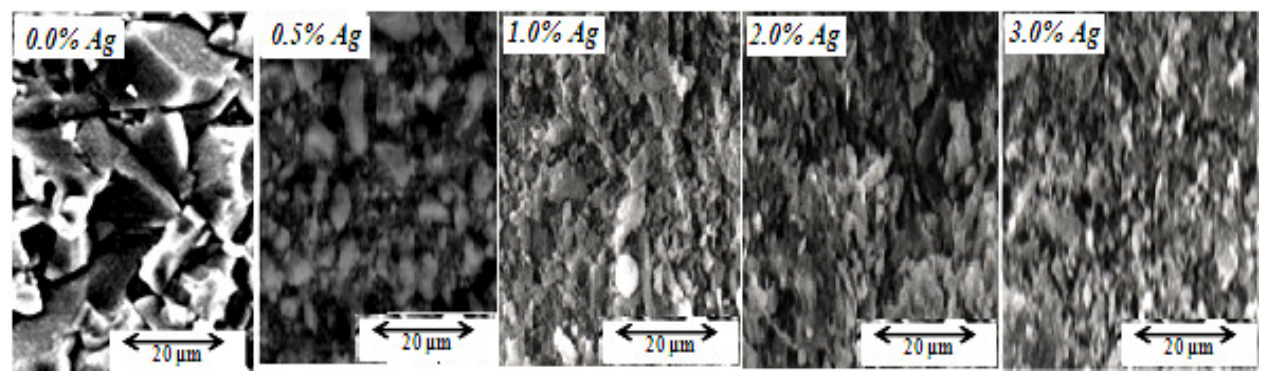

Figure: 6 Micrographs of the sintered samples at $1500{ }^{\circ} \mathrm{C}$

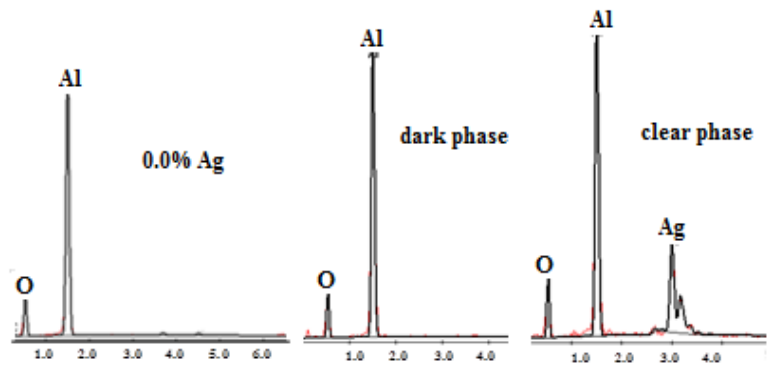

Figure: 7 EDX microanalysis corresponding at the sintered samples at $1500{ }^{\circ} \mathrm{C}$ for 2 hours

\section{Fracture Toughness}

In Fig. 8 are shown, the values of fracture toughness as a function of Ag content in the samples, as well as the temperature and time of sintering. In the samples with different contents of $\mathrm{Ag}$ and sintered at $1500{ }^{\circ} \mathrm{C}$ for $2 \mathrm{~h}$ (Fig. 8a), in relation with the fracture toughness positive values up to $400 \%$ are achieved compared to the monolithic alumina. This increase is even greater in sample with 3.0 wt. \% Ag. These results are consistent with the results of the density measurements and microstructure observations, where it is shown that for the sample with $3.0 \mathrm{wt}$ \% $\mathrm{Ag}$ the controlled grain growth and the homogeneous distribution of Ag accentuate the obtainment of dense bodies with homogeneous microstructures, conditions that facilitate the toughening of alumina by the silver. For samples with inclusions of 0.0 wt. $\%$ and 0.5 wt. \% Ag sintered for $2 \mathrm{~h}$ as a function of temperature (Fig. 8b), it is observed a considerable negative effect of Ag inclusions and of the temperature on fracture toughness. The sintered samples at $1500{ }^{\circ} \mathrm{C}$ as a function of sintered time show similar behavior. Probably here the fact that silver is boiling is not conducive to favor the toughening of alumina. In the revision of Ighodaro and Okoli, several authors have determined that the toughening mechanism in this kind of composites is due to the deflection of cracks owing to metallic bridges formed by the metal used as alumina strengthener. 


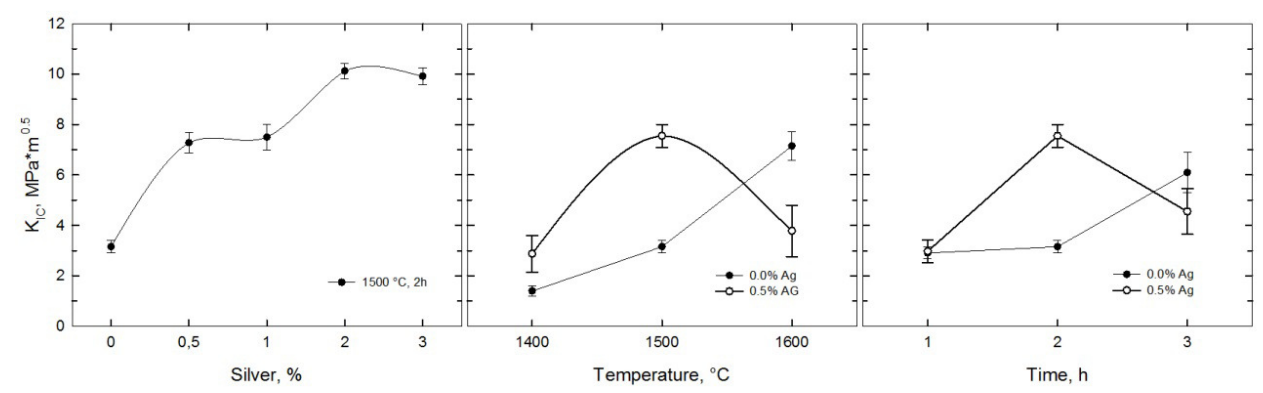

Figure: 8 Fracture toughness of the composites $\mathrm{Al}_{2} \mathrm{O}_{3}-\mathrm{Ag}$

\section{Conclusions}

Through the processing methodology proposed, dense alumina-based composites toughened with $\mathrm{Ag}$ nanoparticles were obtained.

The fracture toughness of the $\mathrm{Al}_{2} \mathrm{O}_{3}$ was improved up to $400 \%$ with the reinforcement of the same by means of $\mathrm{Ag}$ nanoparticles homogeneously distributed in the ceramic matrix.

Probably toughening mechanism of $\mathrm{Al}_{2} \mathrm{O}_{3}$ is owing to metallic bridges formed by the presence of ductile silver particles in the ceramic matrix.

\section{Acknowledgments}

Authors would like to thank to CONACyT, for its support for the accomplishment of this research work through Project 132406.

\section{References}

1. Auerkari, P. (1996) "Mechanical and physical properties of engineering alumina ceramics", Technical Research Centre of Finland, 3-36.

2. Liu, C, Zhang, J, Sun, J and Zhang, X. (2007) "Addition of Al-Ti-B master alloys to improve the performances of alumina matrix ceramic materials", Ceramic International, 33 1319-1324.

3. Oh, S. T, Sekino T. and Niihara, K. (1998) "Fabrication and mechanical properties of $5 \mathrm{vol} \%$ copper dispersed alumina nanocomposite", Journal European Ceramic Society, 18 31-37.
4. Naga, S. M, El-Maghraby, A and El-Rafe, A. M (2007) "Properties of Ceramic-Metal Composites Formed by Reactive Metal Penetration", Am. Cerm. Bull., 86, 4.

5. Li, J., Sun, J. and Huang L. (2002) “ Effects of ductile cobalt on fracture behavior of $\mathrm{Al}_{2} \mathrm{O}_{3}$-TiC Ceramic", Materials Science and Engineering, A323, 17-20.

6. Miranda, J.G, Soto A.B. and Rocha. E. (2006) "Production and characterization of $\mathrm{Al}_{2} \mathrm{O}_{3}-\mathrm{Cu}$ composite materials", Journal Ceramic Processing Research, 7 311-314.

7. Daguano, J.K.M.F, Santos, C.R, Souza, C, Balestra, R.M, Strecker, K. and Elias, C. N. (2007) "Properties of $\mathrm{ZrO}_{2}-\mathrm{Al}_{2} \mathrm{O}_{3}$ composite as a function of isothermal holding time", International Journal Refractory Metals Hard Mater, 25 374- 379.

8. Ighodaro, O.L. and Okoli, O.I. (2008) "Fracture toughness enhancement for alumina systems: a review", International Journal Applied Ceramic Technology, 313323.

9. Ko, S. J. Min, K. H. Kim, Y. D. and Moon, I-H. (2002), "A Study on the Fabrication of $\mathrm{Al}_{2} \mathrm{O}_{3} / \mathrm{CuO}$ Nanocomposite and its Mechanical Properties", J. Ceram. Proc. Res., 3.

10. Agrawal, P. and Sun, C. T. (2004) "Fracture in metal-ceramic composites", Composites Science and Technology 64, 1167-1178.

11. Konopka, K. and Szafran M. (2006) "Fabrication of $\mathrm{Al}_{2} \mathrm{O}_{3}-\mathrm{Al}$ composites by infiltration method and their 
characteristics", Journal Materials Processing Technology, 175, 266-270.

12. Sternizke, M. Knechtel, M Hoffman, M. Broszeit, E. and Rodel, J. (1996), "Wear Properties of Alumina/Aluminum Composites with Interpenetrating Networks", J. Am. Ceram. Soc., 79.

13. Marci C. and Katarzyna. P. (2007) "Processing, microstructure and mechanical properties of $\mathrm{Al}_{2} \mathrm{O}_{3}-\mathrm{Cr}$ nanocomposite", Journal European Ceramic Society, 27, 1273-1277.

14. Lieberthal M.I. and Kaplan, K. (2001) "Processing and properties of $\mathrm{Al}_{2} \mathrm{O}_{3}$ nanocomposites reinforced with submicron $\mathrm{Ni}$ and $\mathrm{NiAl}_{2} \mathrm{O}_{4}{ }^{\prime \prime}$, Materials Science Engineering, A302, 83-91.
15. Sekino, T. Nakajima, T. Ueda S. and Niihara, K., (1997), "Reduction and Sintering of a Nickel-Dispersed-Alumina Composite and its Properties", J. Am. Ceram. Soc., 80.

16. Travirskya, N., Gotmanb I., Claussen, N. (2003) "Alumina-Ti aluminide interpenetrating composites: microstructure and mechanical properties", Materials Letters, 57, 34223426.

17. Evans A.G. and Charles, E.A. (1976) "Fracture toughness determination by indentation", Journal of American Ceramic Society. 59, 371-372. 